\section{DENGUE, ZIKA E CHIKUNGUNYA - DESAFIOS DO CONTROLE VETORIAL FRENTE À OCORRÊNCIA DAS TRÊS ARBOVIROSES - Parte I}

Mesmo antes da introdução do vírus Chikungunya (CHIKV) e do vírus Zika (ZIKV) nas Américas e no Brasil entre 2013 e 2015, com registro de grandes epidemias $^{(1-3)}$, já havia consenso de que o modelo tradicional de controle vetorial não era capaz de impedir isoladamente a expansão geográfica da dengue para áreas até então indenes ${ }^{(4,5)}$.

Por outro lado, a comunidade acadêmica concluía que tampouco uma iniciativa global de imunização, com introdução em larga escala de vacinas contra a dengue, diminuiria consideravelmente a transmissão do vírus (DENV), quando vista dissociada de outras intervenções ${ }^{(6)}$.

A combinação entre um controle vetorial mais eficiente, que impacte na força de transmissão da doença, com a vacinação de grandes contingentes populacionais, que diminua a proporção de suscetíveis, parece ser uma estratégia promissora ${ }^{(6,7)}$. No entanto, realisticamente, a falta de uma vacina eficaz e custo-efetiva contra os quatro sorotipos do DENV e a indisponibilidade de tratamento e imunobiológicos específicos contra o CHIKV e ZIKV ainda afirmam o protagonismo do combate ao Aedes aegipti, como estratégia central de contenção das arboviroses. Porém, o controle vetorial só terá êxito se conseguir incorporar novas tecnologias e ferramentas que possam, em articulação com as já em vigor, alcançar resultados mais satisfatórios, que comprovadamente diminuam a carga da doença e não apenas melhorem indicadores entomológicos ${ }^{(7)}$.

\section{Arboviroses: a magnitude do problema}

A dengue é a doença viral transmitida por artrópodes (arbovirose) responsável pelo maior número de casos e mortes no mundo, representando um grave problema de saúde pública de escala global ${ }^{(7)}$. $\mathrm{O}$ aumento exponencial da incidência da doença e sua expansão geográfica impressionam, quando se sabe que no final dos anos de 1960 apenas nove países haviam registrado surtos com transmissão autóctone. Ao se saltar para 2016, a dengue é endêmica em mais de 120 países, com 100 milhões de casos estimados a cada ano e quatro bilhões de pessoas vivendo em áreas consideradas de risco de infecção pelo $\operatorname{DENV}^{(4,6,8)}$. O Brasil responde por cerca de $70 \%$ do total de casos notificados nas Américas a cada ano. Em 2010, vinte e cinco anos após a reemergência da doença no país, mais de um milhão de casos foram notificados pelos estados brasileiros, com sobrecarga dos serviços de saúde, refletida em quase cem mil hospitalizações, e 678 óbitos, metade deles de menores de $42 \operatorname{anos}^{(9)}$.

A potencial associação entre o ZIKV e a ocorrência de microcefalia e outras alterações congênitas em fetos e bebês infectados por transmissão vertical nas Américas levou a Organização Mundial de Saúde a decretar esta como uma situação de Emergência de Saúde Pública de Importância Internacional (ESPII) em fevereiro de $2016^{(10,11)}$. A associação que seria reconhecida como de natureza causal pelo U.S Centers for Disease Control and Prevention (CDC) e pela OMS dois meses depois, havia sido sugerida por neurologistas brasileiros a partir de setembro

\section{Editorial}

1) Universidade de Fortaleza - UNIFOR Fortaleza (CE) - Brasil

2) Secretaria Municipal de Saúde de Fortaleza - SMS - Fortaleza (CE) - Brasil

3) Faculdades Nordeste DeVry Brasil Fanor Devry - Fortaleza (CE) - Brasil

4) Universidade Estadual do Ceará - UECE - Fortaleza (CE) - Brasil 
de 2015, com base no aumento de casos de microcefalia em áreas com histórico de epidemia prévia pelo $\mathrm{ZIKV}^{(10-}$

13). Em agosto de 2016, o Ministério da Saúde informava 1806 casos confirmados de microcefalia e ou alterações do Sistema Nervoso Central, sugestivos de infecção congênita acumulados desde o início da contagem em novembro de $2015^{(14)}$.

O ZIKV foi isolado pela primeira vez no Brasil em amostras de sangue obtidas em março de 2015 na Bahia ${ }^{(15)}$, mas relatos de casos de uma doença exantemática desconhecida remontam ao final de 2014 e é provável que sua introdução no Brasil tenha ocorrido de fato em $2013^{(12,16)}$. O Brasil naquele momento passou então a evidenciar em alguns estados a circulação simultânea de três arbovírus, pois também já havia transmissão autóctone do vírus Chikungunya (CHIKV) desde setembro de 2014 (2). Ao longo de 2015 e 2016, surtos explosivos de febre de Chikungunya ocorreram em diversos Estados do Nordeste Brasileiro. Apenas nesse último ano foram mais de 170.000 casos prováveis no $\mathrm{Brasil}^{(17)}$.

As razões que justificam a rápida disseminação das arboviroses são complexas e não satisfatoriamente esclarecidas. Porém, pode-se afirmar que além de fatores intrínsecos relacionados à própria patogenicidade dos agentes, mudanças climáticas, demográficas e sociais têm contribuído para esse processo. Em especial, o aumento do fluxo de pessoas entre países (movimento migratório ou por lazer) parece ter sido determinante na introdução tanto do CHIKV quanto do ZIKAV nas Américas ${ }^{(2,16)}$. A urbanização acelerada sem planejamento apropriado na maioria dos países em desenvolvimento, por exemplo, relaciona-se com o aumento das infecções por DENV, por expandir o habitat dos vetores primários, principalmente o Aedes aegypti, em áreas densamente povoadas ${ }^{(18,19)}$. A circulação de vírus emergentes em áreas onde o mosquito transmissor é endêmico, o saneamento precário e a população totalmente suscetível permite exacerbar essa associação.

Esse tema, atualmente, desperta dia a dia novos estudos e pesquisas, dado seu impacto na saúde mundial, não se esgotando neste Editorial, permitindo assim, que a discussão continue o que será realizado no próximo número da Revista Brasileira em Promoção da Saúde.

\section{REFERÊNCIAS}

1. Cardoso CW, Paploski IAD, Kikuti M, Rodrigues MS, Silva MMO, Campos GS, et al. Outbreak of exanthematous illness associated with Zika, Chikungunya, and Dengue viruses, Salvador, Brazil. Emerg Infect Dis. 2015;21(12):2274-6.
2. Honório NA, Câmara DCP, Calvet GA, Brasil P. Chikungunya: an arbovirus infection in the process of establishment and expansion in Brazil. Cad Saúde Pública. 2015;31(5):906-8.

3. Zanluca C, de Melo VCA, Mosimann ALP, dos Santos GIV, dos Santos CND, Luz K. First report of autochthonous transmission of Zika virus in Brazil. Mem Inst Oswaldo Cruz. 2015;110(4):569-72.

4. Bhatt S, Gething PW, Brady OJ, Messina JP, Farlow AW, Moyes CL, et al. The global distribution and burden of dengue. Nature. 2013;496(7446):504-7.

5. Morrison AC, Zielinski-Gutierrez E, Scott TW, Rosenberg R. Defining challenges and proposing solutions for control of the virus vector Aedes aegypti. PLoS Med. 2008;5(3):e68.

6. Reiner RC, Achee N, Barrera R, Burkot TR, Chadee DD, Devine GJ, et al. Quantifying the epidemiological impact of vector control on dengue. PLoS Negl Trop Dis [Internet]. 2016 [acesso em 2016 Ago 24];10(5):e0004588. Disponível em: http://dx.plos. org/10.1371/journal.pntd.0004588

7. Achee NL, Gould F, Perkins TA, Reiner RC, Morrison AC, Ritchie SA, et al. A critical assessment of vector control for dengue prevention. PLoS Negl Trop Dis. 2015;9(5):e0003655.

8. Brady OJ, Gething PW, Bhatt S, Messina JP, Brownstein JS, Hoen AG, et al. Refining the global spatial limits of dengue virus transmission by evidence-based consensus. PLoS Negl Trop Dis. 2012;6(8):e1760.

9. Siqueira JB Jr, Vinhal LC, Said RFC, Hoffmann JL, Martins J, Barbiratto SB, et al. Dengue no Brasil: tendências e mudanças na epidemiologia, com ênfase nas epidemias de 2008. In: Ministério da Saúde (BR). Saúde Brasil 2010: uma análise da situação de saúde e de evidências selecionadas de impacto de ações de vigilância em saúde. Brasília: Ministério da Saúde; 2010. p. 157-71 [acesso em 2016 Ago 24]. Disponível em: http://bvsms.saude.gov.br/bvs/publicacoes/saude brasil_2010.pdf

10. França GVA, Schuler-faccini L, Oliveira WK, Henriques CMP, Carmo EH, Pedi VD, et al. Congenital Zika virus syndrome in Brazil: a case series of the first 1501 livebirths with complete investigation. Lancet. 2016;388(10047):891-7.

11. Castro MC. Zika virus and health systems in Brazil: from unknown to a menace. Heal Syst Reform [Internet]. 2016 [acesso em 2016 Ago 24];2(2):119-22. Disponível em: http://www.tandfonline.com/doi/pdf/1 0.1080/23288604.2016.1179085. 
12. Oliveira WK, Cortez-Escalante J, Oliveira WTGH, Carmo GMI, Henriques CMP, Coelho GE, et al. Increase in reported prevalence of microcephaly in infants born to women living in areas with confirmed zika virus transmission during the first trimester of pregnancy - Brazil, 2015. MMWR Morb Mortal Wkly Rep. 2016;65(9):242-7.

13. Schuler-Faccini L, Ribeiro EM, Feitosa IM, Horovitz DD, Cavalcanti DP, Pessoa A, et al E. Possible association between Zika virus infection and microcephaly-Brazil, 2015. MMWR Morb Mortal Wkly Rep 2016;65(3):59-62.

14. Ministério da Saúde (BR). Monitoramento dos casos de microcefalia no Brasil. Inf Epidemiol [Internet]. 2016 [acesso em 2016 Ago 24];38:1-5. Disponível em: http://combateaedes.saude.gov.br/images/sala-desituacao/informe_microcefalia_epidemiologico38.pdf

15. Campos GS, Bandeira AC, Sardi SI.Zika virus outbreak, Bahia, Brazil. Emerg Infect Dis. 2015;21(10):1885-6.

16. Faria NR, Azevedo RSS, Kraemer MUG, Souza R, Cunha MS, Hill SC, et al. Zika virus in the Americas: Early epidemiological and genetic findings. Science [Internet]. 2016 Mar 24 [acesso em 2016 Ago 24]. Disponível em: http://science.sciencemag.org/content/ early/2016/03/23/science.aaf5036.abstract
17. Ministério da Saúde (BR), Secretaria de Vigilância em Saúde. Boletim Epidemiológico - Monitoramento dos casos de dengue, febre de chikungunya e febre pelo vírus Zika até a Semana Epidemiológica 27. Bol Epidemiológico [Internet]. 2016 [acesso em 2016 Ago 24];47(31):1-7. Disponível em: http://portalsaude.saude.gov.br/images/pdf/2016/ agosto/10/2016-026--2-.pdf

18. Gubler DJ. Dengue and dengue hemorrhagic fever. Clin Microbiol Rev. 1998;11(3):480-96.

19. Halstead SB. Controversies in dengue pathogenesis. Paediatr Int Child Health. 2012;32(Suppl 1):5-9.

\section{Endereço para correspondência:}

Antonio Silva Lima Neto

Universidade de Fortaleza - UNIFOR

Curso de Medicina

Rua Desembargador Floriano Benevides Magalhães, 221

$-3^{\circ}$ andar

Bairro: Edson Queiroz

CEP: 60.811-690 - Fortaleza - CE - Brasil

E-mail: tanta26@yahoo.com 
